\title{
An Analytical Study of Improving Beam-Column Joints Behavior Under Earthquakes
}

\author{
Mohamed I.S. Elmasry ${ }^{1(\bowtie)}$, Ahmed M. Abdelkader ${ }^{1}$, \\ and Essam A. Elkordy ${ }^{2}$ \\ ${ }^{1}$ Arab Academy for Science, Technology \& Maritime Transport (AASTMT), \\ Alexandria, Egypt \\ elmasryi@_aast.edu \\ 2 Alexandria University (AU) President, Alexandria, Egypt \\ esmelkordi@yahoo.com
}

\begin{abstract}
Many existing worldwide Reinforced Concrete (RC) structures, such as non-ductile RC frames, were designed for gravity loads only during the 1950 s through 1970s or earlier. Due to variations in the identification of seismic active zones by national codes, such structures may not satisfy the current design requirements, especially when lying in a recently identified seismic active zone. This is because such structures, as a result of poorer reinforcement detailing, may generally do not possess the adequate ductility and strength needed to withstand an expected earthquake. Consequently, older RC frames may undergo substantial damage during earthquakes. One of the main damage aspects in such case is clear cracks around and within the beam-column connections. This is the case where the failure of beam-column joints is governed by bond and shear failure mechanisms which are usually brittle. This may be attributed to inadequate shear reinforcement in the beam-column joints region. Accordingly, several techniques of repairing and strengthening beam-column joints in older $\mathrm{RC}$ frames have been reported especially in earthquake prone countries. In this paper, a finite element model for an exterior beam-column joint is presented to simulate the behaviour of such joints in older gravity load designed RC frame structures. Several specimens are studied, one for the unstrengthened case, and others represent strengthened cases with different techniques. Studied strengthening techniques include using banded joints with CFRP sheets as a proposed technique, or joints reinforced with steel jackets as observed from older research in literature. Each case is modelled then analysed when loaded incrementally till failure. The stress and deformation results are evaluated then compared for each case. Numerical results show that the beam-column joint strengthened with CFRP can increase their structural stiffness, strength and energy dissipation capacity in contrast to other techniques. The proposed strengthening technique is even advantageous for practical requirements.
\end{abstract}

Keywords: Retrofitting - RC frames - Beam-column joint - CFRP • Earthquake 


\section{Introduction}

Reinforced Concrete (RC) structures including residential, administrative as well as historic and transportation structures widely exist worldwide. Each of these structures has its own role and importance. These structures thus need to be conserved against sudden failures that would cause consequent human life and economic losses. In the meantime, earthquakes may abruptly occur anywhere around the globe. The effect of earthquakes on concrete structures varies, and ranges from mild responses for welldesigned structures to severe responses with extensive damage in case of poorly designed structures.

In addition, one of the popular RC structural systems is the moment resisting frame system. This is the case such that many moment resisting RC frames were designed in the last century or earlier and still exist worldwide. Meanwhile, such older RC frames may not satisfy the current seismic design requirements, and do not possess adequate ductility. Previous research studies attributed that to inadequate shear reinforcement in the beam-column joint region, as stated in Alemdar and Sezen (2010) and Ghobarah and Said (2002). The behavior of the beam-column joint in RC frames is thus a crucial point that requires good design and detailing when strengthening RC moment resisting frames (Kam et al. (2011), Alemdar and Sezen (2010), and Sasmal et al. (2011a)). Several techniques of repairing and strengthening of RC joints, to better withstand earthquakes, have been reported in earlier research in the literature. Some techniques used steel jackets as Jalil et al. (2014) and Sasmal et al. (2011b), while others used Concrete jacketing as Karayannis et al. (2008), and sometimes FRP wrapping as Naveeena and Ranjitham (2016), and Sasmal et al. (2011b).

\subsection{Problem Definition and Research Objectives}

Prior to modern codes that include detailed information for designing structures under seismic loads, older RC frame structures were designed only for gravity loads. This is even the case when considering that the seismic active zones varied in the national codes by time, such that some older structures are presently lying in active seismic zones, though this was not the case in the past. Such existing RC frame structures, though performing well under conventional gravity load case, could lead to questionable structural performance under earthquakes. In most cases, those structures are vulnerable to any moderate or major earthquake, and thus need immediate assessment and retrofitting to avoid a sudden full or partial collapse scenario bringing considerable losses in human lives and economic assets.

In this paper, objectives include developing an effective rehabilitation to strengthen beam-column joints in older structures to improve their seismic performance in terms of lateral strength and serviceability. Accordingly, an analytical model of a beamcolumn joint is proposed, and simulations are performed to study the strength and serviceability of retrofitted beam-column joints using several techniques. The advantages and disadvantages of the different studied strengthening techniques are identified, and results are compared to a proposed strengthening technique using CFRP sheets. 


\section{Literature Review}

\subsection{Beam-Column Joints}

Beam-column joints in $\mathrm{RC}$ moment resisting frames are portions of columns common to beams at their intersections as shown in Fig. 1. These joints in case of Gravity Load Designed (GLD) structures are made of constituent materials that have limited strengths and therefore have limited force carrying capacity. Accordingly, when large lateral forces are applied during earthquakes, such joints may severely get damaged. Moreover, repairing damaged joints is difficult, and thus damage must be avoided by sufficient design and detailing in advance.

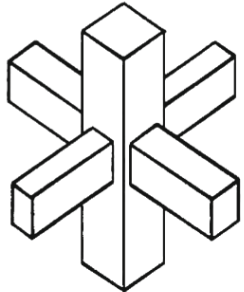

(A) Interior

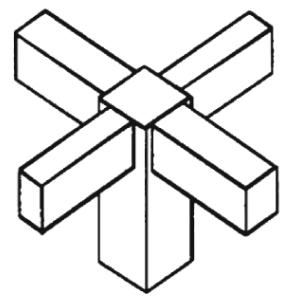

(D) Roof-interior

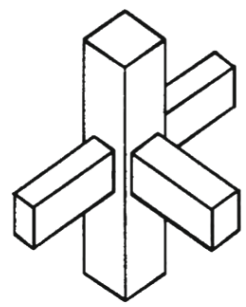

(B) Exterior

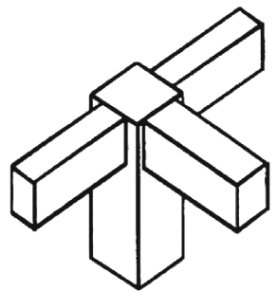

(E) Roof-exterior

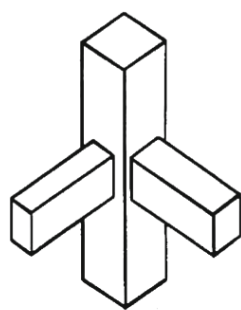

(C) Corner

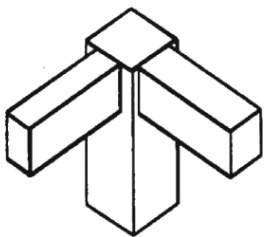

(F) Roof-corner

Fig. 1. Beam column joint connections types

\section{Joints Behavior Under Seismic Loading}

In two-dimensional (2D) frame joints subjected to earthquake loadings, beams and columns experience flexure and shear loadings. Figure 2 shows the forces that could be expected to develop in a 2D frame joint subjected to earthquake and gravity loading. Moreover, when recent seismically designed frames are subjected to moderate and severe earthquake loading, it is expected that the beams will develop flexural strength at the joint while columns will develop moments that approach the yield moment. Meanwhile, in older frames, shear failure of beams and columns or flexural yielding of columns may preclude beams achieving yielding flexural strength. Figure 2(A) shows the expected loads and resultants at the perimeter of the joint region. The load distribution, as shown in Fig. 2(B), can result in severe loading within the joint region. In addition, the moment reversal in the beams and columns results in large shear forces within the joint. 


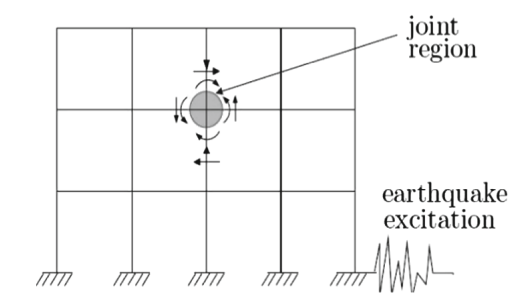

(A) Building frame with joint region

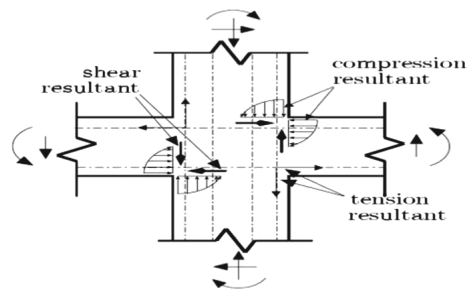

(B) Detailed view of joint region

Fig. 2. Loads in the beam-column joint region

\subsection{Fibre Reinforced Polymer (FRP)}

Fibre Reinforced Polymer (FRP) composites comprise fibres of high tensile strength within a polymer matrix such as epoxy. FRP composites are used in a lot of applications such as aircraft, helicopters, space-craft, satellites, ships, submarines, automobiles, chemical processing equipment, sporting goods and civil infrastructure (Liyoung et al. (2002)), Abhishek (2012), and Sreelatha (2013).

In general, one of the advantages of using FRP products would be strengthening of the existing or new RC structures with the possibility of application without disturbing the existing functionality of the structure (Liyoung et al. (2002) and Sreelatha (2013). In addition, FRP composites had proved to be extremely useful for strengthening of RC structures against both normal and seismic loads as stated in previous research as shown above. Moreover, most of the elements of a structure can be applicably strengthened with FRP composite materials. Currently, this method has been applied to strengthen structural elements as columns, beams, walls, slabs (Nikita et al. (2015), Sasmal et al. (2011b) and Obaidat et al. (2010)). This means in fact that FRP composites can take up the majority of the forces developed in a structure as long as they are transmitted by the strengthened element to the composite one as tensile stresses. Furthermore, strengthening with externally bonded FRP fabric has shown to be applicable to many kinds of structures. The use of external FRP reinforcement may be classified in: (i) Flexural strengthening, (ii) Improving the ductility of compression members, and (iii) Shear strengthening.

Furthermore, Carbon Fibre-Reinforced Polymer, Carbon Fibre-Reinforced Plastic, or Carbon Fibre-Reinforced Thermoplastic (CFRP, CRP, CFRTP) are extremely strong and light FRP which contain carbon fibres. This is the case where carbon fibres give CFRP its strength and rigidity in terms of increasing the ultimate stress and elastic modulus respectively. Unlike isotropic materials like steel and aluminium, CFRP has directional strength properties. The properties of CFRP depend on the layouts of the carbon fibre and the proposition of the carbon fibres relative to the polymer. Advantages for CFRP include high tensile strength, high strength to weight ratio, low weight to volume ratio, excellent fatigue behaviour, and quicker application (Naveeena and Ranjitham (2016)). Thus, CFRP composites are able to strengthen beam column joints in terms of the shear capacity and ductility. 


\section{Method Statement}

Within the context of this paper, an exterior beam column connection is studied in both the strengthened and the unstrengthened cases. It is proposed to increase the shear capacity of the beam column joints using CFRP sheets as shown below in this paper in contrast to using steel or FRP jackets as stated earlier in the literature. The studied beam-column connection is modelled and loaded incrementally till failure to simulate the joint strength against overturning moments, and to compare the joint behaviour on using different strengthening techniques versus the unstrengthened case. Results are studied and compared. Moreover, the load deflection response is compared for each of the retrofitted beam-column joints and the unstrengthened joint case.

\subsection{Modelling}

A finite element model using ANSYS® software is generated, and used for testing the beam column connection problem. ANSYS $®$ is a general purpose Finite Element (FE) modelling and analysis software. The properties of the different elements used in the studied model are explained below.

\section{Element Properties}

Concrete is modelled using Solid 65 element, which is a 3-D structural RC solid element. This element is capable of indicating cracking in tension and crushing in compression. The element is defined by eight nodes having three translational degrees of freedom at each node. The important aspect of this element is the treatment of nonlinear material properties. This element is illustrated in Fig. 3.
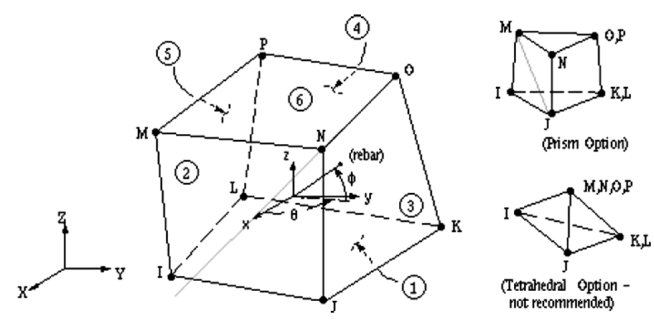

Fig. 3. Solid-65 elements

Discrete modelling is used in modelling the steel reinforcement with assuming that steel and concrete are perfectly bonded. All the reinforcements are modelled separately using LINK8 element, a 3-D spar element which is a uniaxial tension- compression element that is defined by two nodes with three translational degrees of freedom at each node. This LINK8 element is also capable of undergoing plastic deformation.

To model the steel plates at supports and at points of application of the loads, Solid 45, a 3-D structural solid element is used. SOLID 45 is a three-dimensional brick element used to model isotropic solid problems. It has eight nodes, with each node 
having three translational degrees of freedom in the nodal $\mathrm{X}, \mathrm{Y} \& \mathrm{Z}$ directions. This element may be used to analyse large deflection, large strain, and plasticity and creep problems. This element is illustrated in Fig. 4.
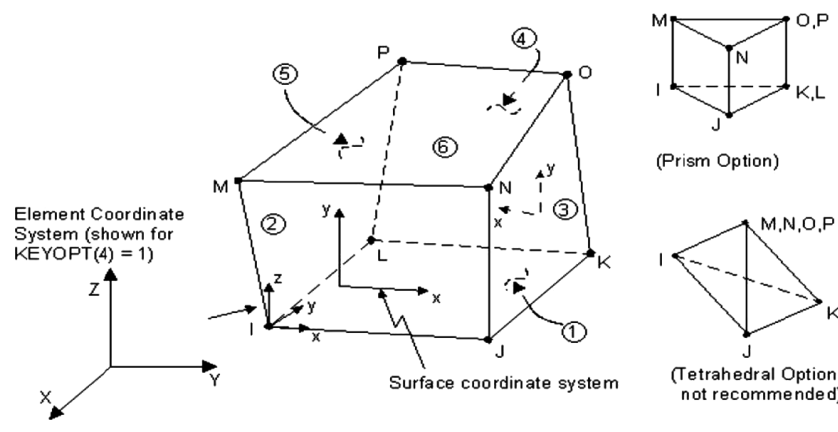

Fig. 4. SOLID-45 elements

Meanwhile, CFRP sheets are modelled using SHELL41 element type. SHELL41 is a 3-D element where the bending of the element is a secondary concern. The element has three degrees of freedom at each node: a translation in the nodal $\mathrm{X}, \mathrm{Y}$, and $\mathrm{Z}$ directions. Figure 5 illustrates the element.

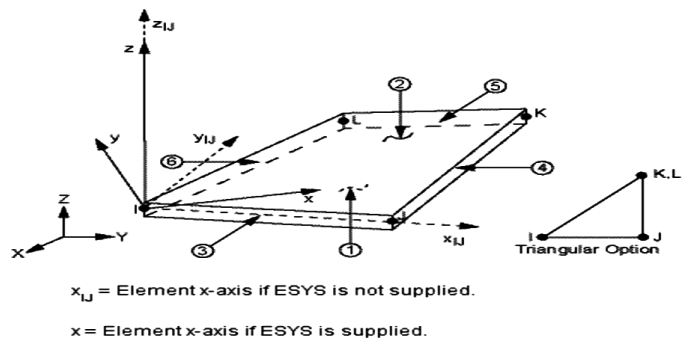

Fig. 5. SHELL41 element

\subsection{Numerical Case Study}

An exterior beam column joint is modelled and analysed using ANSYS $®$. The structural dimensions of the studied beam-column joint, as shown in Fig. 6, are summarized in having a vertical column with a cross section of $300 \mathrm{~mm} \times 300 \mathrm{~mm}$ intersecting a horizontal beam with a $300 \mathrm{~mm} \times 300 \mathrm{~mm}$ cross section. The height of the specimen is $1300 \mathrm{~mm}$ and the beams extend by $500 \mathrm{~mm}$ before and after the connection. The longitudinal reinforcement of the column is 8 T16 rebar as shown in Fig. 6, and the shear reinforcement is $8 \mathrm{~mm}$ diameter stirrups with a spacing of $50 \mathrm{~mm}$. The beam steel reinforcement is 4 T16 rebar as shown in Fig. 6, and the shear reinforcement is $8 \mathrm{~mm}$ diameter stirrups with a spacing of $50 \mathrm{~mm}$. The reason for having 
excessive shear reinforcement in the beam and the column is to enforce the shear cracks to be initiated within the beam-column joint zone rather than in the beam or the column. The cubic strength of concrete is $20 \mathrm{MPa}$ which is typical in GLD older structures, while the yield strength of the steel reinforcement is $360 \mathrm{MPa}$.
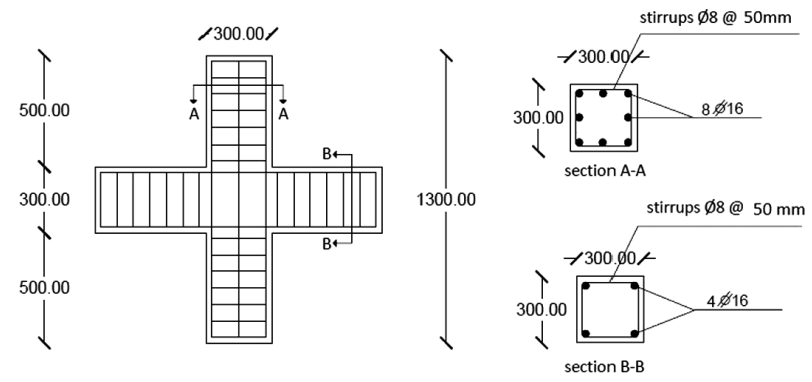

Fig. 6. Studied beam-column dimensions and reinforcement details

The bottom and top of the column is considered constrained in three dimensions $X$, $\mathrm{Y}, \mathrm{Z}$ using fixation end plates as shown in Fig. 7. Incrementally increasing concentrated loads are assumed to act on the specimen at the two cantilevering ends in opposite directions, to double the resulting moments on the connection. A steel plate as shown in Fig. 7 is added at the expected loading location in order to avoid stress concentration problems. This provides a more even stress distribution over the loading area.

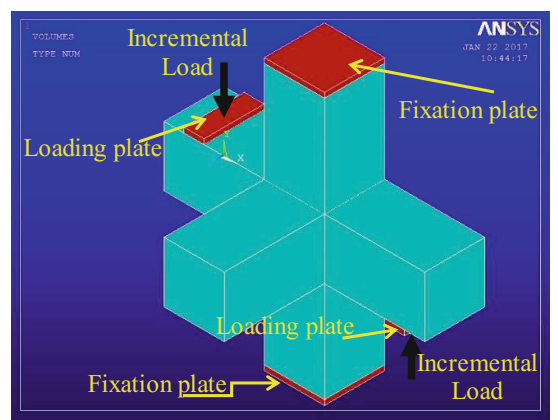

(A) Control specimen model

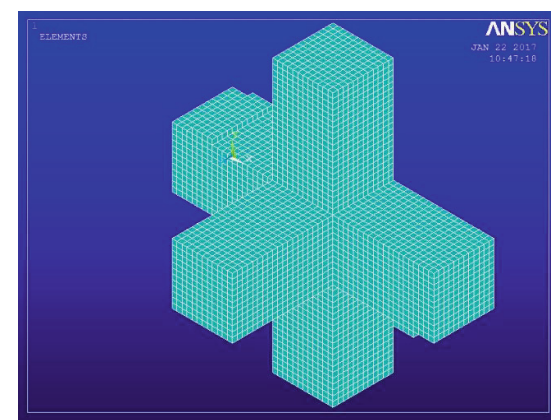

(B) Mesh model for control specimen model

Fig. 7. The exterior beam column joint control model (specimen-1)

The fixation plates and steel plates are modelled using Solid45 elements. Figure 7 (A) shows the control specimen-1 model. It is important to note that FE modelling of beam-column joints in ANSYS® typically consists of three stages: selection of element type; assigning material properties; and modelling the geometrical mesh. In addition, the meshing process of the structure must be optimized to not only help in reducing 
considerable amount of time, but also in reducing the memory requirements of the system and to link structural elements together. Figure 7(B) shows the mesh model for the control specimen-1 model.

\section{Retrofitting with Prestressed Steel Angles}

The dimensions and reinforcement details of this retrofitted specimen are the same as the control specimen except for the added steel angles and plates. Figure 8 shows the exterior beam column joint model retrofitted specimen-2. Figure $9(\mathrm{~A}-\mathrm{C})$ shows the specimen-2 model and mesh model (Jalil et al. (2014)). Steel plate and angles used are of yield strength of $360 \mathrm{MPa}$.
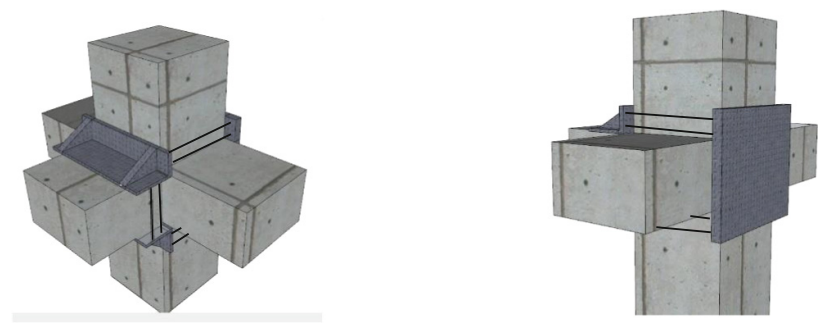

Fig. 8. The exterior beam column joint model retrofitted specimen-2

\section{Retrofitting with Surface CFRP Sheets}

The dimensions and reinforcement remain the same as the control specimen except for the added surface CFRP sheet at the outer side of the connection which extends $10 \mathrm{~cm}$ to the left and right sides of the column. Figure 10(A) shows the retrofitted specimen-3 while Fig. 10(B) shows the mesh model for the retrofitted specimen-3 (Niroomandi et al. 2010). The thickness of the CFRP sheet is considered $1 \mathrm{~mm}$.

\section{Retrofitting with Steel Jacket}

The dimensions and reinforcement details of this retrofitted specimen were the same as the control specimen except for the added steel jacket. Figure 11(A,B) shows the retrofitted joint model (specimen-4). Figure 11(B) shows Mesh model for the retrofitted joint (Robert and Prince (2010)). Steel plates used are of yield strength of $360 \mathrm{MPa}$.

\section{Retrofitting with Reinforced CFRP Diagonal Wrapping}

This retrofitting technique is proposed in this paper. The concrete dimensions and reinforcement details of this retrofitted specimen-5 are the same as the control specimen. However, in this specimen-5, CFRP sheets diagonally reinforce the beam- column joint. In addition, webbed built up angles and covering plates, as shown in Fig. 12, are used as a bearing for the CFRP sheets to get wrapped around the columns at the beam-column connection. Figure 13 shows the mesh model for the retrofitted exterior beam column joint specimen-5. The thickness of the CFRP sheet is considered $1 \mathrm{~mm}$. The modulus of elasticity (E) for CFRP is taken as $24000 \mathrm{MPa}$ in the longitudinal direction and $18581 \mathrm{MPa}$ in the transversal sides. 


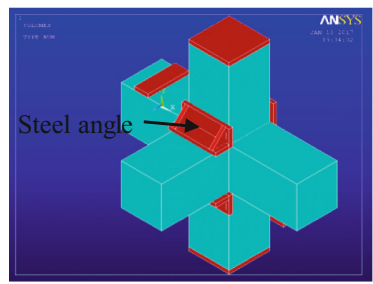

(A)

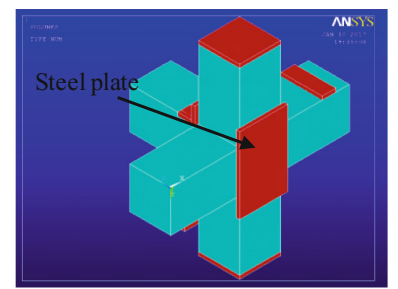

(B)

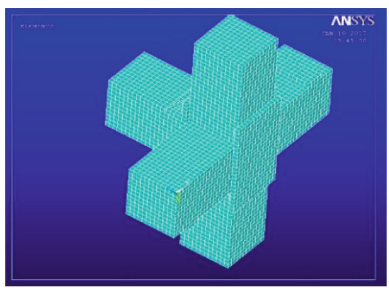

(C)

Fig. 9. Retrofitted specimen-2 and mesh model

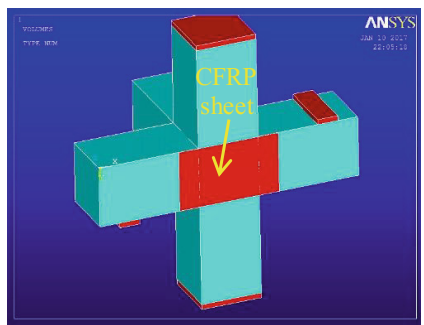

(A)

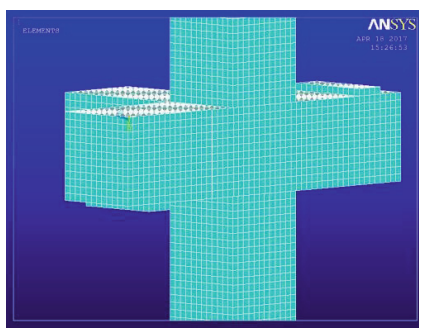

(B)

Fig. 10. Retrofitted specimen-3 and mesh model

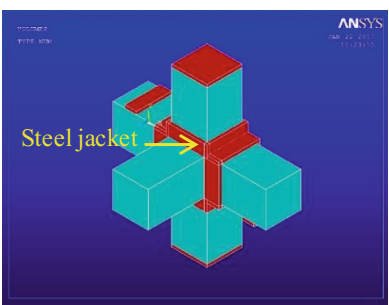

(A)

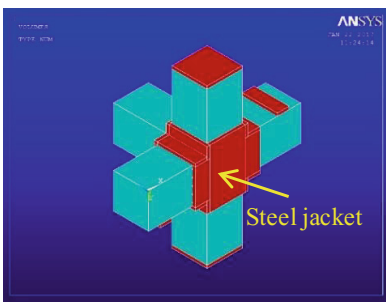

(B)

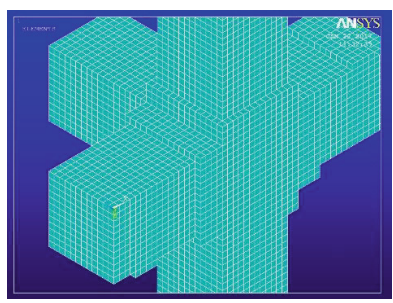

(C)

Fig. 11. Retrofitted specimen- 4 and mesh model

\section{Analysis of Results}

Typical crack outputs of the ANSYS® model for the beam-column joint control specimen are shown in Fig. 14. Meanwhile, Fig. 15 shows the cracks in concrete within the beam column joint for the case of retrofitting with prestressed steel angles (specimen-2). In addition, Fig. 16 indicates the cracks propagation for the case of retrofitting with surface CFRP sheets (specimen-3). Moreover, Fig. 17 shows the cracks in the model for the steel jacket retrofitting case. Finally, Fig. 18 shows the crack pattern in the model for the case of retrofitting with the proposed technique of using diagonal wrapped CFRP sheets (Fig. 19). 


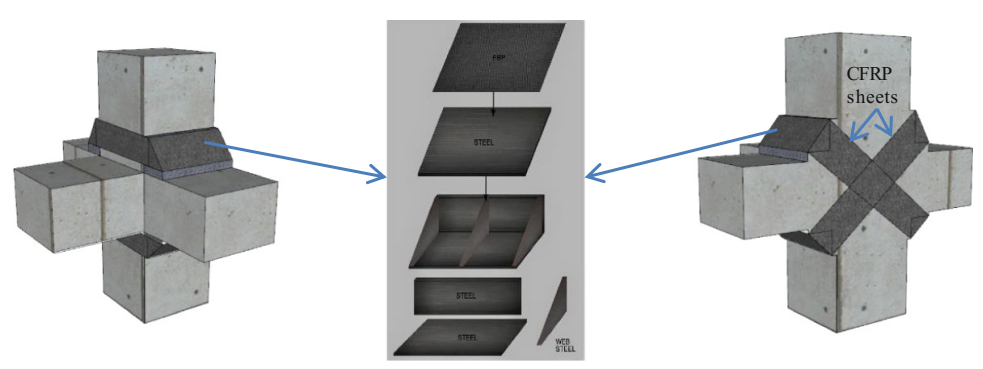

Fig. 12. Proposed retrofitted specimen-5
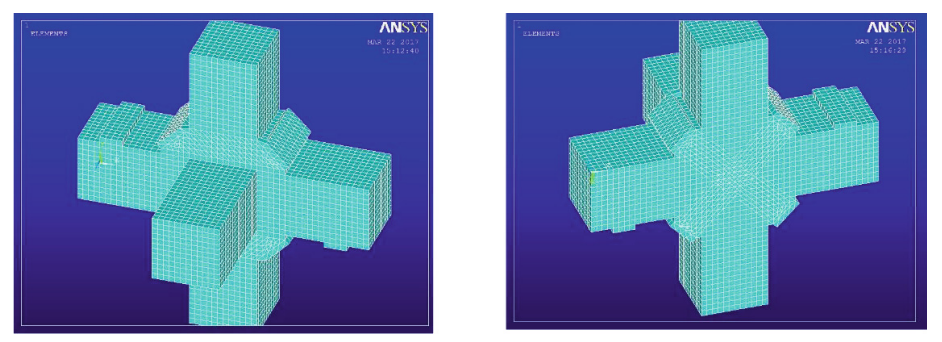

Fig. 13. Mesh model of the proposed retrofitted specimen-5

From the above mentioned figures, it is clear the cracks were concentrated for the unretrofitted case that showed the lowest strength. In spite of the fact that cracks propagation are much less in the case of specimen-4, yet, the ductility was less than the case of the other specimens which undergo higher deflections. The cracks in the case of specimen-5 are more than the case of specimen-4, however, there is not clear difference in terms of the strength of the specimen.

Moreover, by comparing the results shown in the load-deflection curve, as shown in Fig. 20, for the different specimens, it is clear that specimen-4 showed the highest strength, though the difference in strength with the case of specimen-5 is clearly small. Furthermore, specimen- 5 showed more ductile behavior than the case of specimen- 4 though both showed higher strength than the other retrofitting techniques. Except for a small improvement in ductility, there seems to be no clear difference in the response between the unstrengthened specimen-1 and that of specimen-3 uptill the load of nearly $11.5 \mathrm{kN}$. The response of specimen-2 did not differ a lot from that of specimen- 3 . However, the response of specimens 3 and 2 indicate higher strength and better ductile behavior.

In summary and as clear from Fig. 20, it can be concluded that the retrofitting technique used in specimen-5 may be considered the best among the different specimens. This is the case especially that applying the proposed retrofitting technique in specimen-4 for GLD structures may not be practical due to clear difficulties in applying without harming or varying the structures facades. In contrast, retrofitting using the technique of diagonal wrapped CFRP sheets can be easily applied without varying the old facades. 

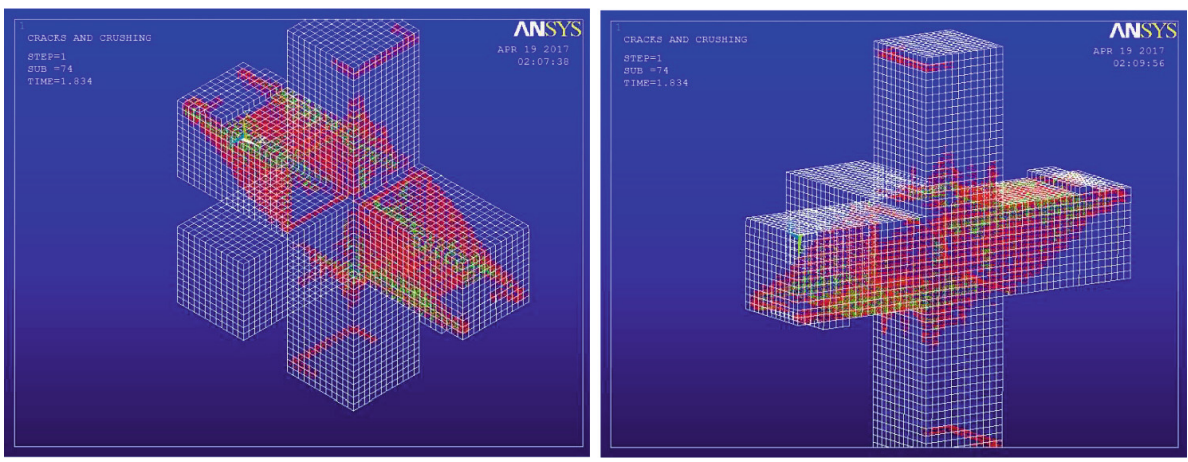

Fig. 14. Resulting cracks for the beam-column joint control specimen
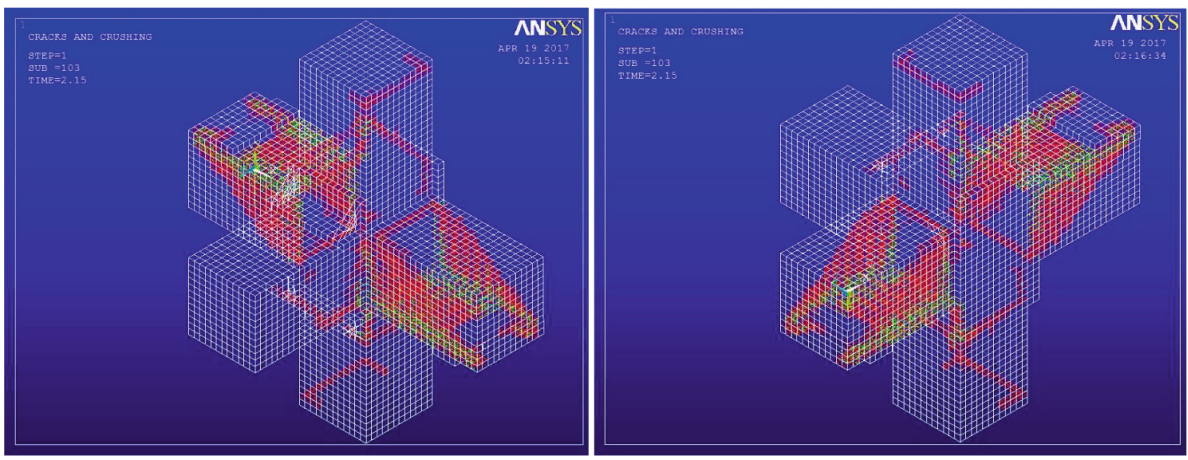

Fig. 15. Resulting cracks for the retrofitted joint with prestressed steel angles
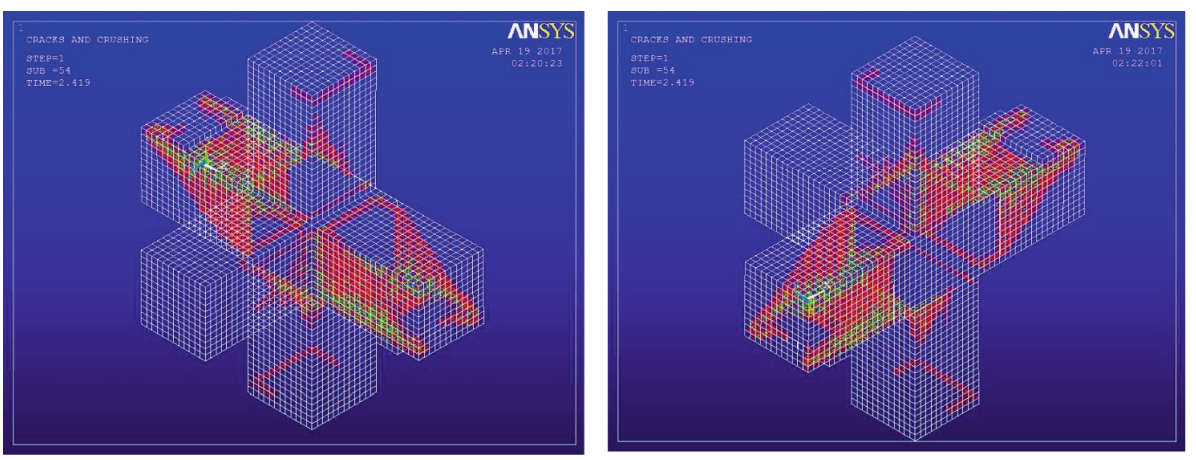

Fig. 16. Resulting cracks for the retrofitted joint with surface CFRP sheets (specimen-3) 

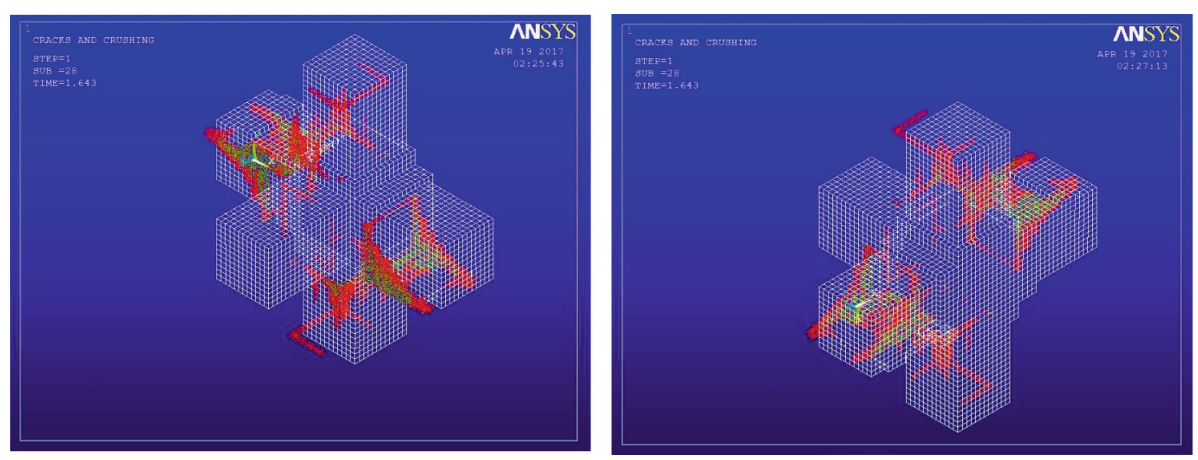

Fig. 17. Resulting cracks for the retrofitted joint with steel jacket (specimen-4)
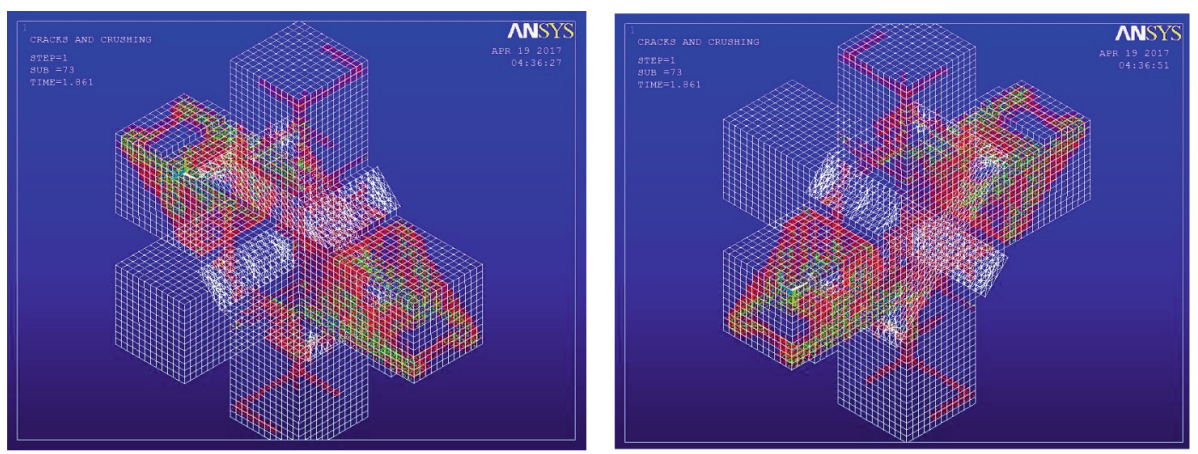

Fig. 18. Resulting cracks for the retrofitted joint with reinforced CFRP diagonal wrapping (specimen-5)
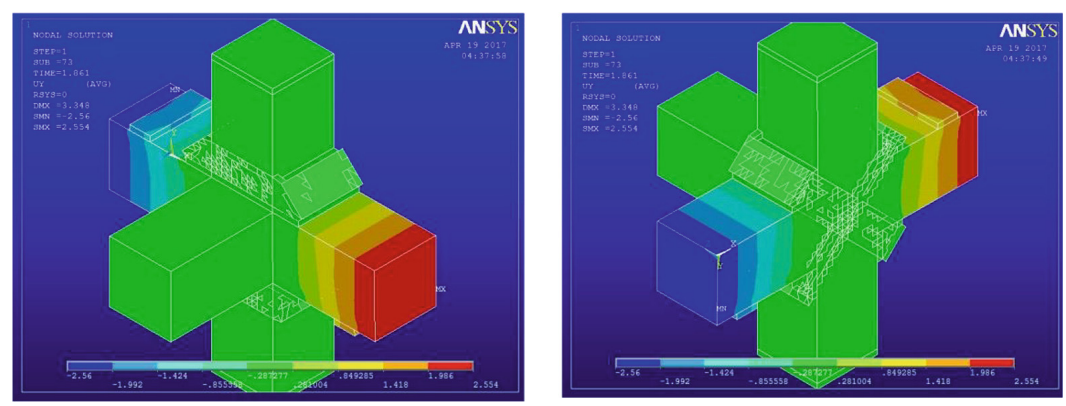

Fig. 19. Y-displacement component for retrofitted specimen-5 


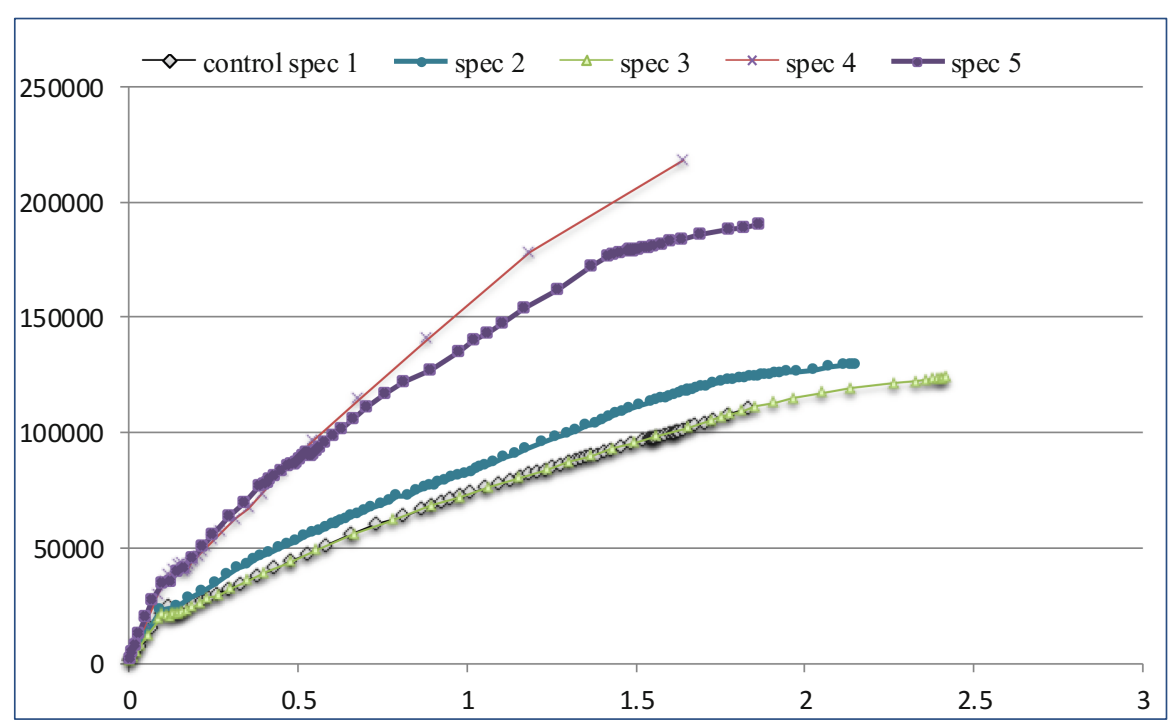

Fig. 20. Comparison between Load - deflection curve for all retrofitting cases

\section{Conclusion}

A survey study was undergone in this paper to identify a suitable retrofitting technique for beam-column joints. Different retrofitting techniques were tested based on previous studies from the literature together with a proposed retrofitting technique using reinforced CFRP diagonal wrapping. Results indicate that beam-column connections strength can clearly increase by using steel jacketing or the proposed technique of wrapping CFRP sheets in a diagonal setup to be perpendicular to the expected shear cracks in the beam-column joint zone. Furthermore, using the proposed technique proved to show better ductile response than other techniques suggested in some previous research related to the same study point. From the overall study, it can be concluded that the strengthening with CFRP sheets as proposed will increase the serviceability of the structure without damaging the facades.

\section{References}

Naveeena, N., Ranjitham, M.: Numerical study on retrofitting of beam column joint strengthened with CFRP. Int. Res. J. Eng. Technol. (IRJET) 3, 914-920 (2016)

Alemdar, F., Sezen, H.: Shear behavior of exterior reinforced concrete beam-column joints. Structural Engineering Mechanics 35(1), 123-126 (2010)

Ghobarah, A., Said, A.: Shear strengthening of beam-column joints. Eng. Struct. 24, 881-888 (2002) 
Sasmal, S., Balthasar, N., Rmanjaneyulu, k., Constanze, R., Srinivas, V., Lakshmanan, N., Nagesh, R.: Upgradation of gravity load designed subassemblages subjected to seismic type loading. Compos. Struct. 93, 1561-1573 (2011a)

Sasmal, S, Ramanjaneyulu, K., Novak, B., Srinivas, V., Kumar, K.S., Korkowski, C.: Seismic retrofitting of nonductile beam-column sub-assemblage using FRP wrapping and steel plate jacketing. Constr. Build. Mater. 25, 175-182 (2011b)

Jalil, S., Abdollah, H., Mohammd, S.: Seismic retrofit of external RC beam-column joints by joint enlargement using prestressed steel angles. Eng. Struct. 81, 265-288 (2014)

El-Amoury, T., Ghobarah, A.: Seismic rehabilitation of beam-column joint using GFRP sheets. Eng. Struct. 24, 1397-1407 (2002)

Karayannis, C.G., Chalioris, C.E., Sirkelis, G.M.: Local retrofit of exterior RC beam-column joints using thin RC jackets - an experimental study. Earthq. Eng. Struct. Dyn. 37(5), 727746 (2008)

Ghobarah, A., Said, A.: Seismic rehabilitation of beam-column joints using FRP laminates. J. Earthq. Eng. 5(1), 113-129 (2001)

Liyoung, T., Adrian, M., Michael, B.: 3D Fibre Reinforced Polymer Composites. Elsevier Science Ltd., Langford lane (2002)

Sreelatha, V.: Experimental study on shear strengthening of RC T-beams with web openings using frp composites. MTech thesis, Department of Civil Engineering, National Institute of Technology, ROURKELA, R0URKELA-769-008, ODISHA, INDIA, January 2013 (2013)

Kotsovou, G., Mouzakis, H.: Exterior RC beam-column joints: new design approach. Eng. Struct. 41, 307-319 (2012)

Malek, A., Saadatmanesh, H.: Ultimate shear capacity of RC beams strengthened with web bonded FRP plates. ACI Struct. J. 95, 391-399 (1998)

Antonopoulos, P., Triantafillou, T.: Analysis of FRP-strengthened RC beam-column joints. J. Compos. Constr. 6(1), 41-51 (2002)

Buyle-Bodin, F., David, E., Ragnea, E.: finite element modelling of flexural behaviour of externally bonded CFRP reinforced concrete structures. Eng. Struct. 24, 1423-1429 (2002)

Niroomandi, A., Maheri, A., Maheri, M., Mahini, S.: Seismic performance of ordinary RC frames retrofitted at joints by FRP sheets. Eng. Struct. 32, 2326-2336 (2010)

Robert, R., Prince, A.: Finite element modeling on behavior of reinforced concrete beam- column joints retrofitted with carbon fiber reinforced polymer sheets. Int. J. Civil Struct. Eng. 1(3), 576-582 (2010) 